\title{
Quantification of traffic-induced compaction based on soil and agricultural implement parameters
}

\author{
Xianliang Wang ${ }^{*}$, Xiangcai Zhang, Xiaona Lin, Luming Sha, Hanyu Yang, \\ Zhaoyang Guo, Zeyu Chen, Rongyan Sun \\ (College of Agricultural Engineering and Food Science, Shandong University of Technology, Zibo 255000, Shandong, China)
}

\begin{abstract}
Vehicle-induced soil compaction occurs when agricultural machinery is working in the fields. The accumulated soil compaction could destroy soil structure and inhibit crop growth. The low degree of visualization of soil compaction has always been an important reason for restricting the development of compaction alleviation technology. Therefore, the main objective of this study was to predict soil compaction based on soil and agricultural implement parameters. The component of soil compaction prediction includes traffic-induced stress transmission evaluation and the quantitative relationship between soil stress and bulk density. The modified FRIDA model was used to elucidate the soil stress propagation, which has been validated by previous studies. The Bailey formula was used to establish the intrinsic relationship between soil stress and bulk density. The soil uniaxial compression test was applied to obtain the parameters of the Bailey formula, and soil samples were prepared with three different levels of water content. After fitting with the Bailey formula, under the condition that the soil moisture contents were $16 \%, 20 \%$, and $24 \%$, the fitting coefficients of soil bulk density were respectively $0.980,0.959$, and 0.975, which were close to 1 . The results indicated that the Bailey formula could be used to calculate soil bulk density based on the stress conditions of the soil. To verify the practicality of the soil compaction prediction model, a field experiment was carried out in Zhuozhou City, Hebei Province, China. The treatment was set for 1, 3, 5, 7, and 9 times compaction with two different loads of compaction equipment. The results showed that the fit coefficient between the predicted and measured values of soil bulk density was greater than 0.641 . The slope of the equation was greater than 0.782 , proving that the soil bulk density prediction model based on agricultural implements and soil parameters has a good predictive effect on soil bulk density. The soil compaction evaluation model can provide a theoretical basis to further understand the soil compaction mechanism, allowing rational measures of soil compaction alleviation to be made.
\end{abstract}

Keywords: soil traffic-induced compaction, agricultural implement, soil bulk density, no-tillage, soil structure, quantification DOI: $10.25165 /$ j.ijabe. 20201305.5480

Citation: Wang X L, Zhang X C, Lin X N, Sha L M, Yang H Y, Guo Z Y, et al. Quantification of traffic-induced compaction based on soil and agricultural implement parameters. Int J Agric \& Biol Eng, 2020; 13(5): 134-140.

\section{Introduction}

Ideal farmland soil consists of $50 \%$ soil particles and organic matter and $50 \%$ pores (at about $25 \%$ water and $25 \%$ air) ${ }^{[1]}$. With the development of agricultural machinery, the mechanization of crop production will become an inevitable trend ${ }^{[2,3]}$. Therefore, during agricultural machinery operation, the soil is subjected to a serious problem of compaction. Several studies have demonstrated that significant traffic-induced soil compaction could destroy the soil structure, increase soil bulk density, affect soil biodiversity, and reduce crop yield ${ }^{[4-7]}$. Furthermore, soil compaction is one of the main reasons for soil degradation and the decline in cultivated land quality. As such, studying the soil

Received date: 2019-10-26 Accepted date: 2020-07-13

Biographies: Xiangcai Zhang, $\mathrm{PhD}$, Lecturer, research interest: conservation tillage, Email: zxcai0216@163.com; Xiaona Lin, PhD, Lecturer, research interest: agricultural engineering, Email: linxiaona1120@163.com; Hanyu Yang, Undergraduate, research interest: agricultural engineering, Email: 1459556290@ qq.com; Luming Sha, Undergraduate, research interest: agricultural engineering, Email: 1334821879@qq.com; Zhaoyang Guo, Undergraduate, research interest: agricultural engineering, Email: 723354408@qq.com; Zeyu Chen, Undergraduate, research interest: agricultural engineering, Email: 1273958137@qq.com; Rongyan Sun, Undergraduate, research interest: agricultural engineering, Email: 942900570@qq.com.

*Corresponding author: Xianliang Wang, PhD, Lecturer, research interest: soil compaction. Shandong University of Technology, Zibo 255000, Shandong, China. Tel: +86-15264311735, Email: wangxianliang2008@126.com. compaction mechanism and accurately predicting the degree of compaction are both of great significance for soil compaction alleviation.

The process of traffic-induced external force propagated from the subsoil layer to deep soil causes soil compaction during field operations ${ }^{[8]}$. The consequence of soil compaction in agriculture is dependent on soil and agricultural machine characteristics. Many studies on soil compaction have focused on the impact of compaction on soil properties, crop growth effects, and alleviation techniques ${ }^{[9-11]}$. Soil compaction models were able to predict the stress caused by agricultural machinery ${ }^{[12]}$. The ever-improving FRIDA model combined with the Boussinesq equation was used to calculate the soil stress transmitted by the parameters of agricultural tires and implements ${ }^{[13,14]}$. Moreover, numerical analyses have also been widely used to analyze soil compaction. For example, ABAQUS/STANDARD 6.8-1 code was used to construct the soil compaction model, which could predict the soil stress based on tire inflation pressure and tire load ${ }^{[15]}$. However, soil compaction is a phenomenon that destroys the soil structure caused by the interaction between the tire and the soil ${ }^{[16]}$. Soil compaction occurs during stress propagation, which has demonstrated significant correlations with changes in the physical properties of soil. Jan et al. ${ }^{[17]}$ used the REPRO model to determine whether the soil was damaged by soil stress at different depths. Although the soil compaction model can predict the stress state of soil at different depths, it is still difficult to express and 
evaluate soil properties systematically and intuitively.

Soil bulk density and penetration resistance have frequently been used as important indicators of soil compaction, which are closely related to soil porosity ${ }^{[18]}$. Some new technologies with the advantage of visualization have been increasingly used in soil compaction evaluation. For example, Shane ${ }^{[19]}$ proposed monitoring soil compaction in the form of surface waves, where it was found through experimentation that there is a significant difference in shear wave velocity between compacted and non-compacted regions. In recent years, some researchers have also set up a soil structure visualization model (SubVESS) to visually understand soil compaction, which set parameters that were sensitive to soil compaction as an evaluation index ${ }^{[20,21]}$. Peignéetc et al. ${ }^{[22]}$ proposed a conception of a conversion layer between the topsoil and the deep soil and used comprehensive properties, such as the thickness, strength, and depth of the conversion layer, to judge the soil compaction. The process of soil compaction prediction evaluation is complicated, and there exists a series of problems such as large workload and sampling measurement error.

Only a few studies have used soil stress transmission regarding soil structure dynamics to evaluate soil compaction. Further work should be done to establish a quantitative relation between soil bulk density and agricultural machinery. Therefore, the main purposes of this study are (1) to theoretically establish the soil compaction model, which contains the vehicle-induced stress calculation and soil bulk density evaluation based on soil and agricultural implement parameters; (2) to verify the accuracy of the model and improve its adaptability through field experiments. This study made full use of the existing models to integrate different functional models to form a system as a whole, as well as to construct a new understanding of soil compaction evaluation.

\section{Mathematical model}

\subsection{Evaluation of soil stress below tire}

To introduce the concept of tire compaction times into the model, a previous study optimized the FRIDA model and the Boussinesq equation through field experiments and discrete element simulations ${ }^{[23]}$. The vertical stress was calculated by the semi-empirical equation for soil stress transmission given by Söhne ${ }^{[24]}$.

$$
\sum_{i=0}^{n}\left(\sigma_{z}\right)_{i}=\sum_{i=0}^{n} \frac{v P_{i}}{2 \pi r_{i}^{2}} \cos ^{v} \theta_{i}
$$

where, $\sigma_{z}$ is the soil stress transfer coefficient; $\theta$ is the angle between the perpendicular line through load $P_{i}$ and the line connecting load $P$ to the measured point, $\left({ }^{\circ}\right) ; v$ is the stress concentration factor during soil stress transmission, and $r$ is the distance from the load $P$ to the point, $\mathrm{m}$.

Equation (1) was simplified and the stress concentration factor $v$, which is an important parameter for soil stress propagation, was extracted.

$$
v\left(\frac{z}{r}\right)^{v}=\frac{2 \sigma_{z} \pi r^{2}}{\sigma_{0} A}
$$

To remedy the error between the formula and experimental data, a new stress evaluation equation was fitted with a large amount of data obtained through field experiments.

The main forms of the expression are as follows,

$$
\sigma_{z}=\frac{v \sigma_{0} A z^{v}}{2 \pi r^{v+2}}+\left[5 E-05 P^{2}-0.0046 P+0.1517-0.0004 z\right] \ln T
$$

$$
v\left(\frac{\sigma_{z}}{\sigma_{0}}, \frac{z}{r}, A\right)=\frac{3+\ln \frac{z}{r}+\sqrt{6 \ln \frac{z}{r}+\left[\ln \left(\frac{z}{r}\right)\right]^{2}-4 \ln \left(\frac{2 \sigma_{z} \pi r^{2}}{\sigma_{0} A}\right)+17}}{2}
$$

where, $A$ is the tire-soil contact area, $\mathrm{m}^{2} ; \sigma_{0}$ is the tire-soil contact surface stress, $\mathrm{kPa} ; z$ is the depth of the soil, $\mathrm{m} ; T$ is the number of tire compactions, and $\sigma_{z} / \sigma_{0}$ is the soil stress transfer coefficient.

\subsection{Quantifying soil additional compressive stress and bulk} density

The three-parameter model created by Bailey was selected to represent the relationship between the soil additional stress and the soil bulk density change. The experimental data were fitted by the least-squares method. The parameter values of the relationship between the additional stress on the soil and soil bulk density under different water content conditions were obtained, and the parameters in the relationship were quadrupled with the soil water content to determine and fit the relationship between the parameters and the soil moisture content. For the relationship between the applied stress and the soil bulk density, the independent variables are the soil stress and soil moisture content and the dependent variable is the relationship of soil bulk density.

The model relationship is:

$$
\ln (\rho)=\ln \left(\rho_{0}\right)-(A+B \sigma)\left(1-e^{-c \sigma}\right)
$$

where, $\rho_{0}$ is the soil bulk density before loading; $\sigma$ is the additional stress applied; $\rho$ is the soil bulk density after applying compressive stress; and $\mathrm{A}, \mathrm{B}$, and $\mathrm{C}$ are the relationship coefficients.

The model relationship can be used to obtain the soil bulk density value after applying the external stress based on the soil bulk density value before the stress is applied, and the model has a good fit with Bailey. This section is based on the relationship of the model between the additional stress on the soil and the soil bulk density.

\section{Quantitative relations between soil stress and bulk density}

\subsection{Soil sample preparation}

The soil sample was taken by a homemade iron box with the dimensions of $400 \mathrm{~mm} \times 400 \mathrm{~mm} \times 400 \mathrm{~mm}$. The homemade iron box was pressed into the soil by an external force. The undisturbed soil inside the iron box was taken out and taken back to the laboratory for testing. The $20 \mathrm{~cm}$ soil surface of the sampling box was taken out and air-dried with a $5 \mathrm{~mm}$ aperture sieve. The water was evenly sprayed onto the surface of the sieved soil by watering can, and the soil sample was sealed for a period to be fully infiltrated. The infiltrated soil was returned to the sample box for testing. Before the test, the ring cutter method was used to measure the soil bulk density value of $0-20 \mathrm{~cm}$ inside the sample box. The average soil bulk density was $1.10 \mathrm{~g} / \mathrm{cm}^{3}$.

\subsection{Experimental design}

The entire test process was completed by an RGM-4005 microcomputer-controlled by a digital electronic universal material testing machine. The additional stress-applying device for this test was mounted on the mainframe by the clamp-fixing device, the clamp device was connected to the test machine force sensor, and the stress-applying device moved up and down by controlling the beam. The moving speed was $400 \mathrm{~mm} / \mathrm{min}$. The test sets had different loading conditions of $200 \mathrm{~N}, 400 \mathrm{~N}, 600 \mathrm{~N}, 800 \mathrm{~N}$, and $1000 \mathrm{~N}$, and these different conditions controlled the beam of the test machine to move downward. When the stress-applying device came in contact with the soil and reached the set loading condition, the beam was stopped and kept the loaded state for $1 \mathrm{~s}$. 
The beam was unloaded and then the beam was raised. The soil was taken at the center of the load application area by the ring cutter, and the soil bulk density was measured by the drying method (Figure 1).

The soil sample was disturbed after each trial and before the next trial to keep the initial condition consistency of the soil sample.
Finally, the soil bulk density error of each initial state of the test was kept within 15\%. Each test was replicated threefold. Three different soil moisture contents of $16 \%, 20 \%$, and $24 \%$ were set in the experiment. Under the three soil moisture conditions, different pressure strengths were loaded, and the soil additional stress-soil bulk density was calculated for the fitting of the three groups of data.
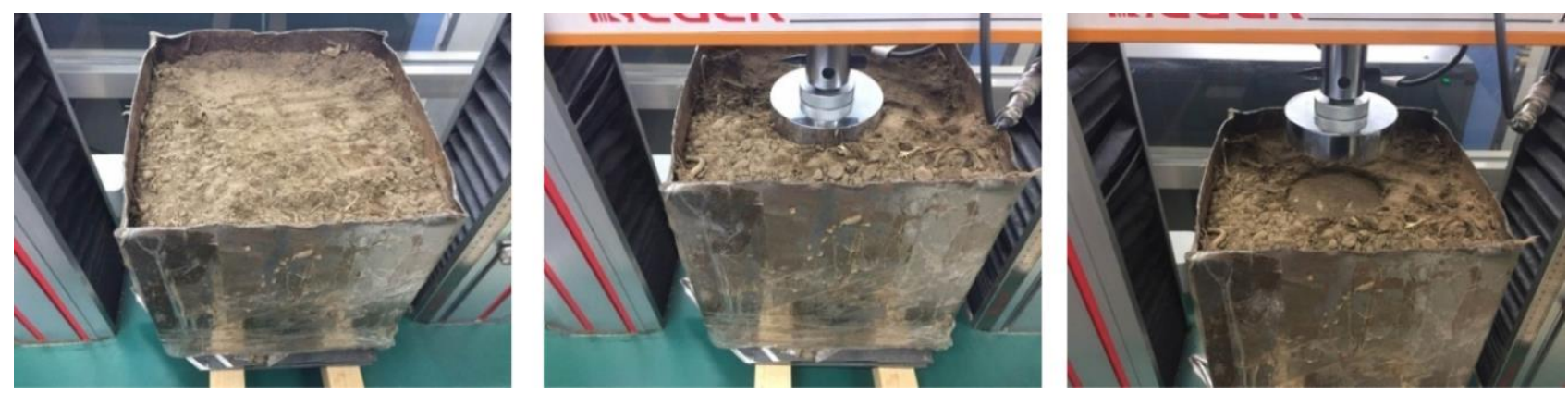

Figure 1 Loading/unloading process in the test

\subsection{Results and discussion}

Table 1 shows the effects of different soil stresses on soil bulk density under different soil moisture conditions. It can be seen from the table that the soil bulk density increased with the increase of soil moisture content and the additional load of soil. The results are consistent with the results of Lestariningsih et al. ${ }^{[25]}$ The soil moisture content mainly affected the internal mechanical characteristics of soil particles so that its ability to resist external damage was reduced, which is more likely to cause changes in soil bulk density. When the additional load increased, the soil structure was destroyed and the bulk density increased.

Under the condition of different soil moisture contents, the soil bulk density was fitted with the additional stress of soil. Table 2 describes the specific information of the fitted soil compaction model parameters.

It can be observed from Figure 2 that under different soil moisture conditions, the soil bulk density increases with the increase of additional soil stress. The Bailey formula was fitted, and under the soil moisture content of $16 \%, 20 \%$, and $24 \%$, the fitting coefficients of soil bulk density were respectively 0.980 , 0.959 , and 0.975 , which were all close to 1 . Consequently, it can be proven that the selected Bailey equation can also be applied to the corresponding relationship between the additional stress on the soil and soil bulk density under different relationships of water content conditions. Soil water content plays an important role in soil compaction by affecting the mechanical strength of soil, which explains the difference in the Bailey equation parameters under different water contents of the soil ${ }^{[26]}$.

Table 1 Effect of additional stress on soil bulk density under different moisture contents

\begin{tabular}{|c|c|c|c|c|c|c|}
\hline Additional load/N & 0 & 200 & 400 & 600 & 800 & 1000 \\
\hline Contact area $/ \mathrm{cm}^{2}$ & 0 & 78.5 & 78.5 & 78.5 & 78.5 & 78.5 \\
\hline Contact surface stress $/ \mathrm{kPa}$ & 0 & 25.5 & 51.0 & 76.5 & 102.0 & 127.5 \\
\hline $20 \%$ moisture content soil bulk density $/ \mathrm{g} \cdot \mathrm{cm}^{-3}$ & 1.08 & 1.198 & 1.267 & 1.349 & 1.399 & 1.413 \\
\hline $24 \%$ moisture content soil bulk density $/ \mathrm{g} \cdot \mathrm{cm}^{-3}$ & 1.10 & 1.206 & 1.288 & 1.363 & 1.424 & 1.455 \\
\hline
\end{tabular}

Table 2 Parameter results of soil compaction model fitting

\begin{tabular}{|c|c|c|c|c|c|c|c|c|c|}
\hline \multirow{2}{*}{ Parameter } & \multicolumn{3}{|c|}{ Soil moisture content $16 \%$} & \multicolumn{3}{|c|}{ Soil moisture content $20 \%$} & \multicolumn{3}{|c|}{ Soil moisture content $24 \%$} \\
\hline & A & B & $\mathrm{C}$ & A & B & $\mathrm{C}$ & A & B & $\mathrm{C}$ \\
\hline Parameter value & -0.087 & -0.0015 & 3.96 & -0.077 & -0.0016 & 3.90 & -0.061 & -0.0018 & 4.01 \\
\hline Standard deviation & 0.0143 & $2.784 \times 10^{-4}$ & 0 & 0.0217 & $2.460 \times 10^{-4}$ & $1.563 \times 10^{-4}$ & 0.0177 & $1.990 \times 10^{-4}$ & $4.632 \times 10^{-4}$ \\
\hline Fitting coefficient & \multicolumn{3}{|c|}{$R^{2}=0.980$} & \multicolumn{3}{|c|}{$R^{2}=0.959$} & \multicolumn{3}{|c|}{$R^{2}=0.975$} \\
\hline
\end{tabular}

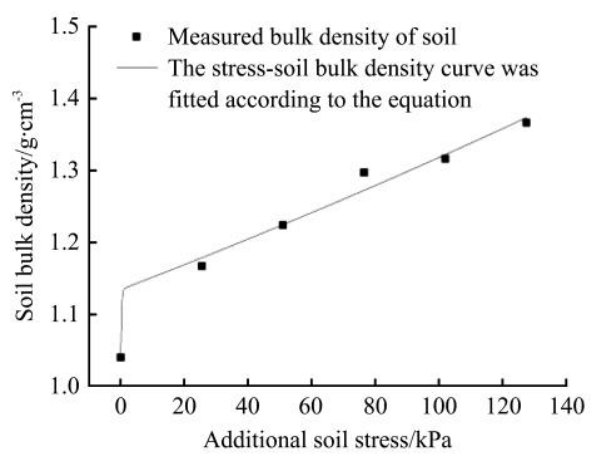

a. Soil moisture content $16 \%$

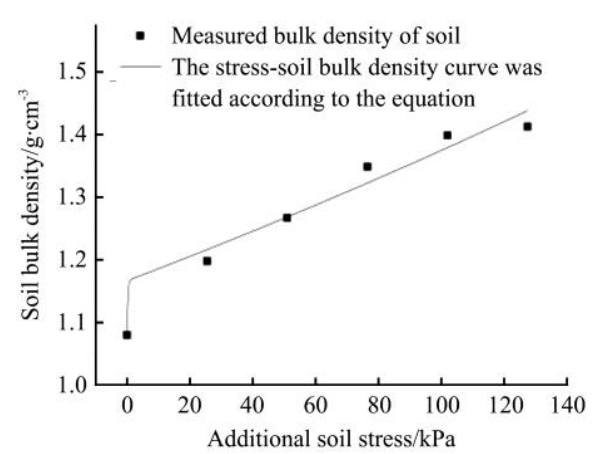

b. Soil moisture content $20 \%$

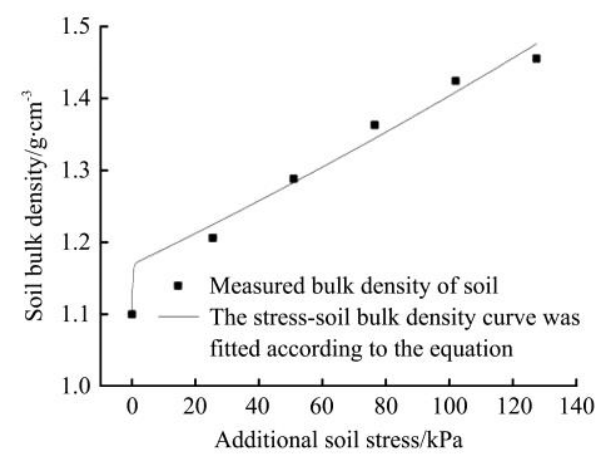

c. Soil moisture content $24 \%$

Figure 2 Soil compaction model fitting process 


\section{Application of soil compaction prediction in practice}

\subsection{Site description and experimental design}

The experiment was conducted in 2016-2017 in the Agricultural Science and Technology Park of Dongchengfang Town, Zhuozhou City, Hebei Province. The test area is a typical warm temperate semi-humid continental monsoon climate with an annual average temperature of $11.4^{\circ} \mathrm{C}$. The annual rainfall is about $450 \mathrm{~mm}$. The test site is flat and the soil texture is light loam. The $\mathrm{pH}$ value is 7.8 , the average field water holding rate is $11.3 \%$, and the wilting moisture content is $1.2 \%$. The heat transfer coefficient was $0.52 \mathrm{~W} / \mathrm{m} \cdot \mathrm{K}$, and the organic matter mass ratio was $1.0 \%-1.9 \%$. The specific soil characteristics of $0-80 \mathrm{~cm}$ are shown in Table 3. The average yield of corn in the past 5 years is $10015.5 \mathrm{~kg} / \mathrm{hm}^{2}$.

The planting system is winter wheat and summer maize for two crops a year. The planting system before the experiment was a no-tillage pattern. The tillage process is corn harvesting, stalk crushing, and weeding in wheat field-wheat harvesting-corn, no-tillage fertilization sowing-spraying, and weeding-corn harvesting. Therefore, except for the natural sedimentation factor, the soil compaction problem in the area was caused by the agricultural machinery walking device. Furthermore, no plow pan phenomenon was presented.

In the test area, there were six different compaction treatments at $0,1,3,5,7$, and 9 compaction times. Each treatment setting was repeated three times, and a completely random principle was adopted between each treatment. The area of each treatment test area was $20 \mathrm{~m} \times 15 \mathrm{~m}\left(300 \mathrm{~m}^{2}\right)$, of which the pressure-free ( $\mathrm{C} 0)$ was the control group. To avoid soil compaction caused by field management, the crop growth belt and the vehicle-induced compaction belt were permanently separated to prevent different treatments. To prevent interference from different processes, there was an isolation strip between each treatment that was $2 \mathrm{~m}$ wide. The specific test layout diagram of each cell is shown in Figure $3 \mathrm{a}$, and the field test ground layout is shown in Figure $3 \mathrm{~b}$.

Table 3 Soil characteristics of test site

\begin{tabular}{|c|c|c|c|c|c|c|c|c|}
\hline \multirow{2}{*}{ Soil depth/cm } & \multirow{2}{*}{ Soil type } & \multicolumn{3}{|c|}{ Mechanical composition/\% } & \multirow{2}{*}{$\begin{array}{c}\text { Bulk weight } \\
/ \mathrm{g} \cdot \mathrm{cm}^{-3}\end{array}$} & \multirow{2}{*}{$\begin{array}{l}\text { Organic matter } \\
/ \mathrm{g} \cdot \mathrm{kg}^{-1}\end{array}$} & \multirow{2}{*}{$\mathrm{pH}$ value } & \multirow{2}{*}{$\begin{array}{l}\text { Soil water } \\
\text { content } / \%\end{array}$} \\
\hline & & $<0.002 \mathrm{~mm}$ & $\geq 0.002-0.02 \mathrm{~mm}$ & $\geq 0.02-2 \mathrm{~mm}$ & & & & \\
\hline $0-20$ & Loam & 10.6 & 40.1 & 49.3 & 1.22 & 11.5 & 7.6 & 15.5 \\
\hline $40-60$ & Sandy loam & 9.8 & 32.8 & 57.4 & 1.42 & 5.1 & 7.5 & 11.9 \\
\hline $60-80$ & Sandy loam & 7.7 & 25.2 & 67.1 & 1.58 & 3.8 & 7.8 & 8.5 \\
\hline
\end{tabular}

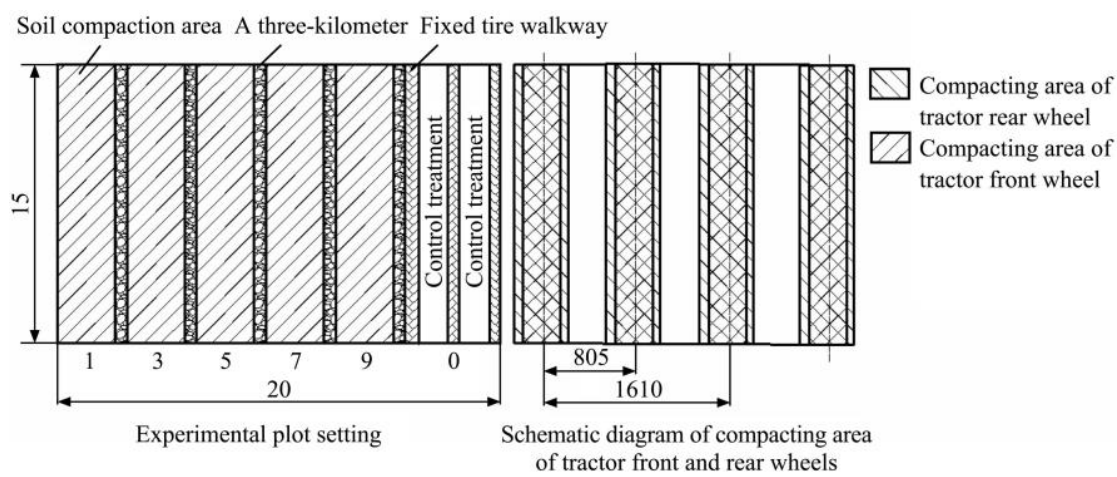

a. Schematic diagram of the specific test layout of the community

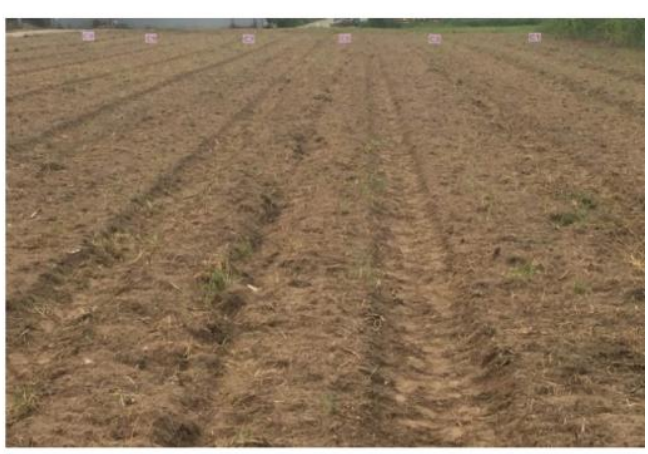

b. Field trial situation

Figure 3 Specific method of field operation

\subsection{Compaction equipment parameters}

The compaction device for each compaction degree was selected from two tractors with different loads and matching tires. The specific parameters are shown in Table 4. The tire-soil contact area and stress calculation are obtained according to the mathematical model. The speed of the tractor was $5.5 \mathrm{~km} / \mathrm{h}$ during the experiment.
To minimize the test error, the test site was homogenized and thoroughly deepened before the start of the experiment.

Soil bulk density was selected as the test index to verify the prediction accuracy of soil bulk density in the soil compaction prediction model. The sampling depth was $0-80 \mathrm{~cm}$, which was sampled once every $20 \mathrm{~cm}$.

Table 4 Test compaction equipment and tire parameters

\begin{tabular}{|c|c|c|c|c|c|c|c|c|}
\hline Test setup & Weight/kg & \multicolumn{2}{|c|}{ Tire type } & $\begin{array}{l}\text { Axle load } \\
/ \mathrm{kN}\end{array}$ & $\begin{array}{l}\text { Tire section width } \\
\qquad / \mathrm{mm}\end{array}$ & $\begin{array}{c}\text { Tire pressure } \\
/ \mathrm{kPa}\end{array}$ & $\begin{array}{l}\text { Tire-soil contact } \\
\text { area } / \mathrm{m}^{2}\end{array}$ & $\begin{array}{c}\text { Contact surface } \\
\text { stress } / \mathrm{kPa}\end{array}$ \\
\hline \multirow{2}{*}{ John Deer 280} & \multirow{2}{*}{1225} & Front wheel & $6.00-16(\mathrm{R}-1)$ & 5.75 & 152.4 & 150 & 0.036 & 160.4 \\
\hline & & Rear wheel & $9.5-24(\mathrm{R}-1)$ & 6.5 & 241.3 & 115 & 0.089 & 72.8 \\
\hline \multirow{2}{*}{ RevoM904 } & \multirow{2}{*}{4155} & Front wheel & $12.4-24$ & 20 & 315 & 85 & 0.15 & 133.3 \\
\hline & & Rear wheel & $16.9-34$ & 21 & 430 & 100 & 0.339 & 61.9 \\
\hline
\end{tabular}

\subsection{Verification results of soil compaction prediction model}

The measured values of the soil bulk density and the model simulation values at different depths under different conditions of compaction were linearly fitted. The fitting results are shown in Figure 4. Under the compaction condition of the Revo M904 tractor, the linear fitting coefficients between the predicted soil bulk density and the measured values of the number of compaction times of $1,3,5,7$, and 9 are $0.715,0.974,0.852,0.772$, and 0.638 , respectively. Under the compaction condition of the John Deere 280 tractor, the linear fitting coefficients between the predicted and measured values of the soil bulk density with the number of compactions at $1,3,5,7$, and 9 times were $0.987,0.827,0.864$, 
0.641, and 0.709, respectively. According to the fitting coefficient value, the John Deere 280 compaction of 7 times had the minimum fitting coefficient between the model predicted value and the measured value of the soil bulk density, which was 0.641 .

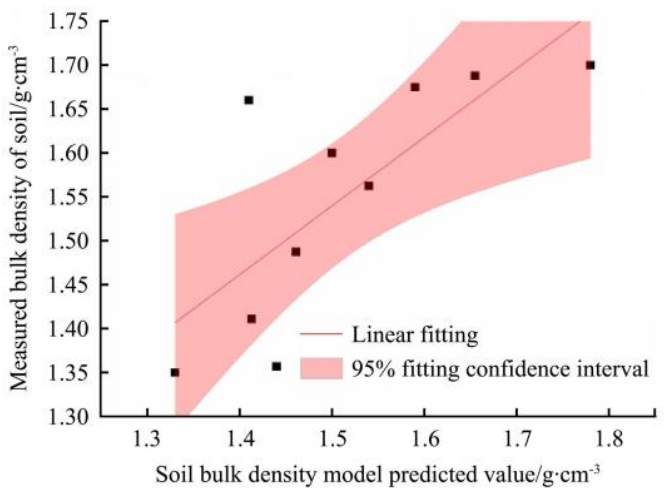

Revo M904

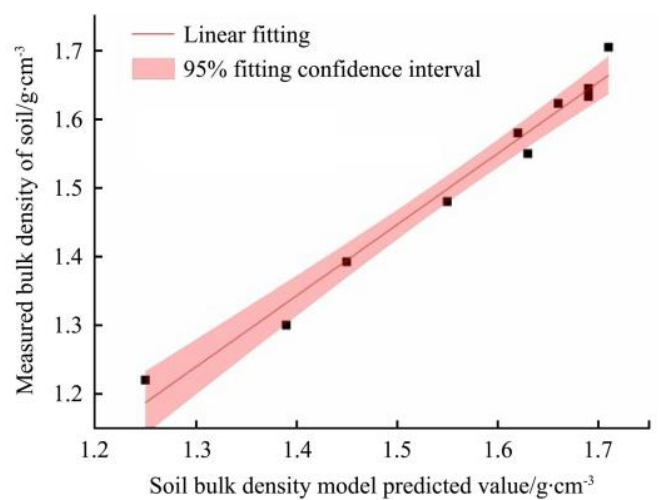

Revo M904

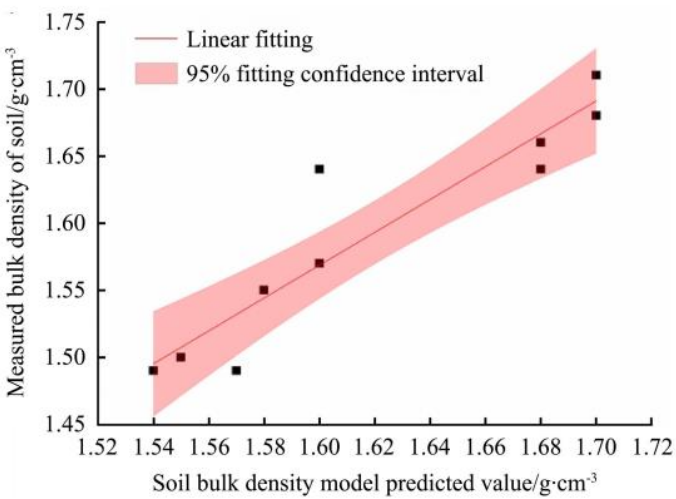

Revo M904

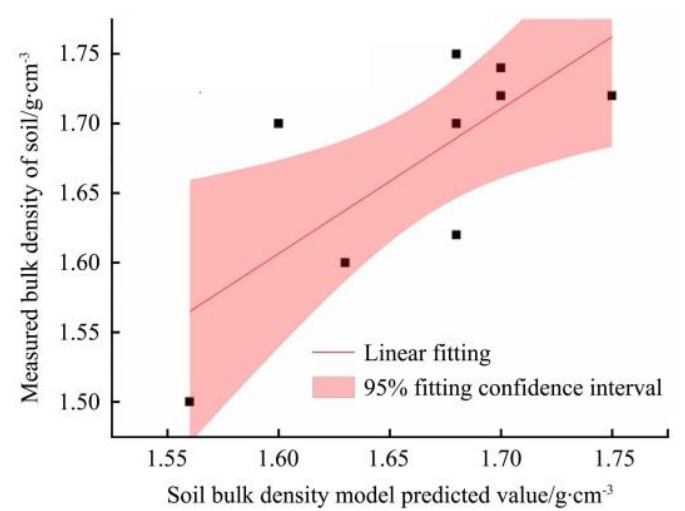

Revo M904
The fitting coefficient was greater than 0.70 , proving that it is feasible for this technology to calculate soil bulk density by agricultural machinery and soil parameters during the processing of loading and unloading.

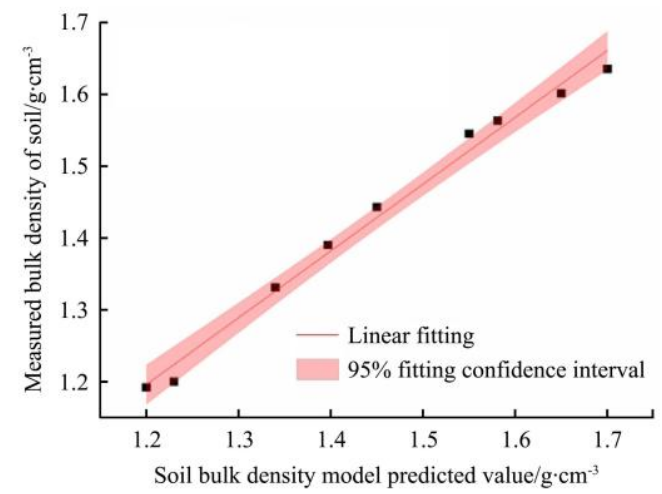

John Deer 280

Compaction 1 time

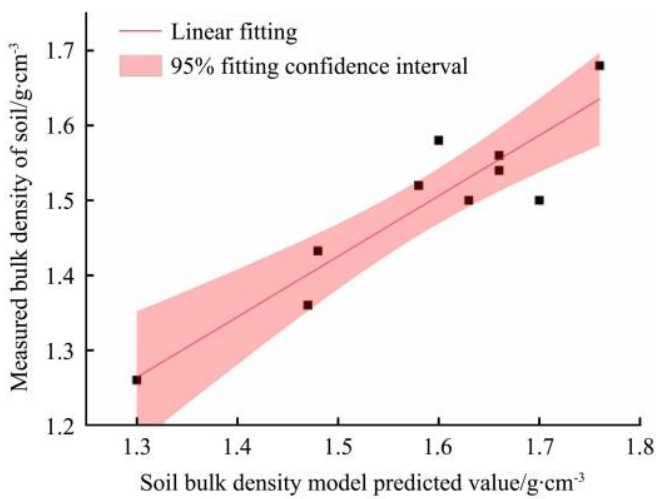

John Deer 280

Compaction 3 time

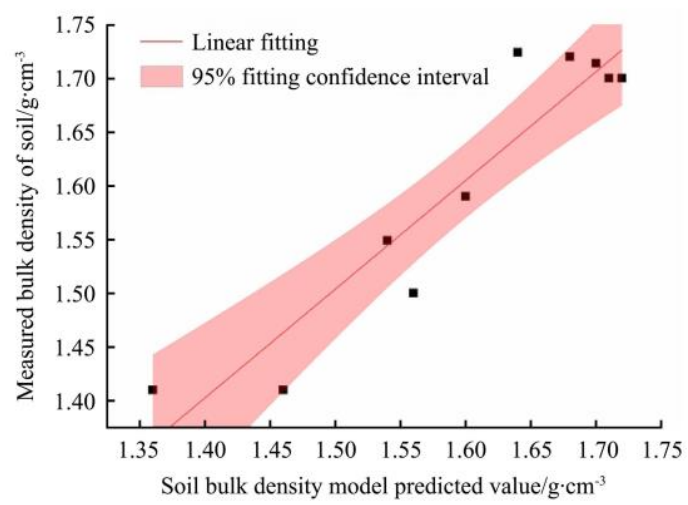

John Deer 280

Compaction 5 time

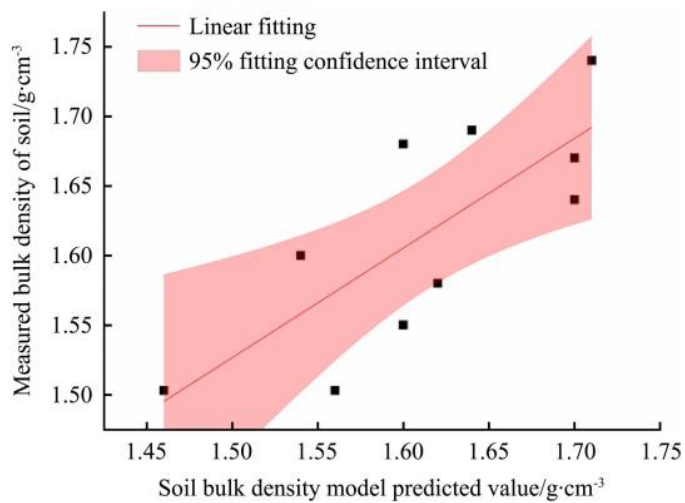

John Deer 280 

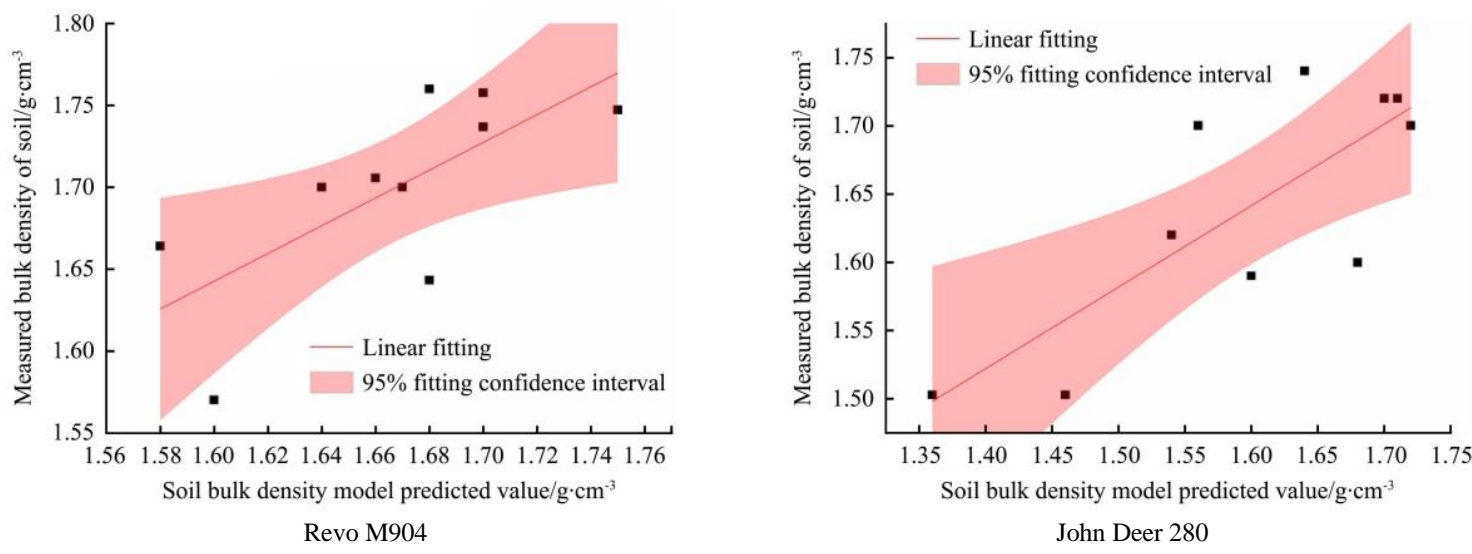

Compaction 9 time

Figure 4 Fitting results of predicted values and measured values of the soil bulk density model

Under the compaction conditions of the Revo M904 tractor, the slopes of the fitted equations between the predicted soil bulk density and the measured values of the number of compaction times of 1, 3, 5, 7 and 9 were $0.782,0.997,0.787,0.961$, and 0.848, respectively. Under the compaction condition of the John Deere 280 tractor, the slopes of the fitted equations between the predicted and measured values of the soil bulk density with the number of compactions at 1, 3, 5, 7, and 9 were, respectively, 0.930, 0.808, $0.989,0.789$, and 0.796 . The results showed that the slope of the fitted equation between the model prediction value and the measured value of the soil bulk density was greater than 0.782 , suggesting that the mathematical model could predict soil bulk density based on agricultural implements and soil characteristics.

This study proposed a mathematical model for predicting vehicle-induced soil compaction. Soil stress produced by loading and unloading during agricultural tire driving was the main reason for constructing the internal relationship between agricultural machinery and soil compaction. Several studies have demonstrated that there are many approaches to calculate the vertical stress distribution at the soil/tire interface and vertical stress transmission. The plastic deformation of soil occurred during the stress propagation in the soil profile. Soil stress-strain is a complex process. The Young's modulus and friction angle had a significant correlation with the bulk density. An exponential model was used to fit the soil stress-strain relationship. Furthermore, the soil water content exhibited quadratic relationships with soil friction angle and cohesion. Therefore, initial relations exist between soil bulk density and vertical stress, which could be expressed as a fitting formula. Huang et al. ${ }^{[27]}$ used the least square method to fit the data of the Bailey three-parameter model and determined the relationship between soil bulk density and stress. To predict the ballast pressure during sowing, Zhang ${ }^{[28]}$ fitted the Bailey model and put up the soil stress-bulk density equation under two different water contents. These studies provided a suitable method for explaining the initial relationship between soil stress and the physical properties of soil.

\section{Conclusions}

In this study, a quantitative evaluation system between tire walking and soil bulk density was constructed by combining the spatial transfer process of soil stress during the tire walking process with the quantitative relationship between soil stress and bulk density. The experimental results of the two parts were verified. The results showed that the calculation results of soil bulk density are within the error range. In a fixed type of land, this method could be used to predict soil compaction. However, it is worth noting that this study only demonstrates that the system method is more accurate and feasible for this particular type of soil. Under other soil type conditions, some parameters of the model need to be optimized and verified.

\section{Acknowledgements}

This work was financially supported by the Science and Technology National Natural Science Foundation of China (Grant No. 51805300) and PhD start-up fund (Grant No. 418032).

\section{[References]}

[1] Abdel-Moghny T, Mohamed R S A, El-Sayed E, Shoukry M, Moustafa G. Effect of soil texture on remediation of hydrocarbons-contaminated soil at El-Minia District, Upper Egypt. ISRN Chemical Engineering, 2012; 2012(2): 1-13.

[2] Zhao Z J, Zou M, Xue L, Wei C G, Li J Q. Simulation analysis of the effect of compaction on soil stress distribution. Transactions of the CSAM, 2012; 43(S1): 13-16. (in Chinese)

[3] Zhang J L, Han W T, Shi S B, Gao F, Zhang Y Z. Experimental study on soil compaction by agricultural machinery. Tractors and farm transporters, 2011; 38(3): 6-7. (in Chinese)

[4] Hamza M A, Anderson W K. Soil compaction in cropping systems a review of the nature, causes and possible solutions. Soil and Tillage Research, 2005; 82(2): 121-145.

[5] Batey T. Soil compaction and soil management a review. Soil Use and Management, 2009; 25(4): 335-345.

[6] Raper R L. Agricultural traffic impacts on soil. Journal of Terra mechanics, 2005; 42(3): 259-280.

[7] Soane B D, van Ouwerkerk C. Soil compaction problems in world agriculture. Developments in Agricultural Engineering, 1994; 11: 1-21.

[8] Zhang L. Response and adaptation mechanism of Festuca Arundinacea to soil compaction on coal waste piles with spontaneous combustion. $\mathrm{PhD}$ dissertation. Beijing: China University of Mining and Technology, 2012; 149p. (in Chinese)

[9] Keller T, Lamandé M. Challenges in the development of analytical soil compaction models. Soil and Tillage Research, 2010; 111(1): 54-64.

[10] Wu Y B, Liu S. Effects of soil compaction on soil properties and plant growth. China Forestry Science and Technology, 2010; 24(1): 15-17. (in Chinese)

[11] Niziolomski J C, Simmons R W, Rickson R J, Hann M J. Tine options for alleviating compaction in wheelings. Soil and Tillage Research, 2016; 161: 47-52.

[12] Schjønning P, Lamandé M, Tøgersen F A, Johan A, Thomas K Modelling effects of tyre inflation pressure on the stress distribution near the soil-tyre interface. Biosystems Engineering, 2008; 99(1): 119-133.

[13] Hemmat A, Adamchuk V I. Sensor systems for measuring soil compaction: Review and analysis. Computers and Electronics in Agriculture, 2008; 63(2): 89-103.

[14] Boussinesq J. Application of potentials to the study of the balance and motion of elastic solids. Paris: Gautiher-Villars, 1885; 721p. 
[15] Omar G C, Ciro E, Carlos A. Recarey M, Guillermo U. Three dimensional finite element model of soil compaction caused by agricultural tire traffic.Computers and Electronics in Agriculture, 2013; 99: 146-152.

[16] Peter B O, Dorothee K, Mathieu L, Trond B, Gareth E. Compaction and sowing date change soil physical properties and crop yield in a loamy temperate soil. Soil and Tillage Research, 2018; 184: 153-163.

[17] Jan R, Hofmann B, Deumelandt P, Frank R, Jana B, Kurt J H. Indicator based assessment of the soil compaction risk at arable sites using the model REPRO. Ecological Indicators, 2015; 52: 341-352.

[18] Newell J P, Whittingham M J, Chambers B J. Visual soil evaluation in relation to measured soil physical properties in a survey of grassland soil compaction in England and Wales. Soil and Tillage Research, 2013; 127: 65-73.

[19] Donohue S, Forristal D, Donohue L A. Detection of soil compaction using seismic surface waves. Soil and Tillage Research, 2013; 128: 54-60.

[20] Obour P B, Schjønning P, Peng Y, Lars J. Subsoil compaction assessed by visual evaluation and laboratory methods. Soil and Tillage Research, 2017; 173: 4-14.

[21] Ball B C, Batey T, Munkholm L J, Guimarães R, Boizard H, McKenzie D. The numeric visual evaluation of subsoil structure (subvess) under agricultural production. Soil and Tillage Research, 2015; 148: 85-96.
[22] Peigné J, Vian J, Cannavacciuolo M, Vincent L, Yvan G, Hubert B Assessment of soil structure in the transition layer between topsoil and subsoil using the profile cultural method. Soil and Tillage Research, 2013 127: 13-25.

[23] Wang X L, Wang Q J, Li H W, He J, Zhang Y F. Research on contact properties of soil-tire based on FRIDA Model. Transactions of the CSAM, 2016; 47(9): 121-127. (in Chinese)

[24] Söhne W. Stress distribution in soil and soil deformation under tractor tyres. Grdlgn. d. Landtechn, 1953; 5: 49-63.

[25] Lestariningsih I D, Hairiah Widianto K. Assessing soil compaction with two different methods of soil bulk density measurement in oil palm plantation soil. Procedia Environmental Sciences, 2013; 17: 172-178

[26] Saffih-Hdadia K, De'fosseza P, Richard G. A method for predicting soil susceptibility to the compaction of surface layers as a function of water content and bulk density, Soil and Tillage Research, 2009; 105: 96-103.

[27] Huang Z X, Chen J, Zhu X F. Study on the problem of stress bulk density under different soil moisture content. Modernizing Agriculture, 2016; 1: 19-20. (in Chinese)

[28] Zhang Q Z. Soil press roller with bionically geometrically structured surfaces. PhD dissertation. Changchun: Jilin University, 2014; 162p. (in Chinese) 